\title{
Working memory deficits, increased anxiety-like traits, and seizure susceptibility in BDNF overexpressing mice
}

\author{
Francesco Papaleo, ${ }^{1,2,4,6}$ jill L. Silverman, ${ }^{3,4}$ Jordan Aney, ${ }^{2}$ Qingjun Tian, ${ }^{2}$ Charlotte \\ L. Barkan, ${ }^{3}$ Kathryn K. Chadman, ${ }^{3,5}$ and Jacqueline N. Crawley ${ }^{3}$ \\ ${ }^{1}$ Department of Neuroscience and Brain Technologies, Istituto Italiano di Tecnologia, 16163 Genova, Italy; ${ }^{2}$ Clinical Brain Disorders \\ Branch; Genes, Cognition and Psychosis Program, Intramural Research Program, National Institute of Mental Health, Bethesda, \\ Maryland 20812, USA; ${ }^{3}$ Laboratory of Behavioral Neuroscience, Intramural Research Program, National Institute of Mental Health, \\ Bethesda, Maryland 20812, USA
}

\begin{abstract}
BDNF regulates components of cognitive processes and has been implicated in psychiatric disorders. Here we report that genetic overexpression of the BDNF mature isoform (BDNF-tg) in female mice impaired working memory functions while sparing components of fear conditioning. BDNF-tg mice also displayed reduced breeding efficiency, higher anxiety-like scores, high self-grooming, impaired prepulse inhibition, and higher susceptibility to seizures when placed in a new empty cage, as compared with wild-type (WT) littermate controls. Control measures of general health, locomotor activity, motor coordination, depression-related behaviors, and sociability did not differ between genotypes. The present findings, indicating detrimental effects of life-long increased BDNF in mice, may inform human studies evaluating the role of BDNF functional genetic variations on cognitive abilities and vulnerability to psychiatric disorders.
\end{abstract}

Brain-derived neurotrophic factor (BDNF) is a member of the neurotrophin family of growth factors and is most highly concentrated in the hippocampus and frontal cortex (Baquet et al. 2004). BDNF has been implicated in a number of processes including cognition, neurogenesis, depression, anxiety, neurodegeneration, diabetes, obesity, seizures, and synaptic plasticity (Genoud et al. 2004; Goldberg and Weinberger 2004; Scharfman 2005; Duman and Monteggia 2006; Martinowich et al. 2007; Schmidt and Duman 2007; Lynch et al. 2008; Chaldakov et al. 2009; Zuccato and Cattaneo 2009). In particular, BDNF is critically involved in learning and memory processes (Bekinschtein et al. 2008; Galloway et al. 2008; Chen et al. 2010; Peters et al. 2010).

Genetic modifications altering BDNF might be important in the development of aberrant cognitive abilities and psychiatric disorders. A human BDNF genetic polymorphism in which a methionine (Met) substitutes for a valine (Val) amino acid, which disrupts activity-dependent BDNF neural secretion (Egan et al. 2003; Chen et al. 2006), is associated with altered cognitive functions and predisposition to psychiatric illnesses such as schizophrenia, Alzheimer's, depression, substance-related, and eating disorders (Egan et al. 2003; Dempster et al. 2005; Gratacos et al. 2007; Fukumoto et al. 2010; Soliman et al. 2010; van Wingen et al. 2010; Verhagen et al. 2010). In mice, reduced genetic expression of BDNF impairs hippocampal-dependent memory processes (Gorski et al. 2003; Monteggia et al. 2004), and the BDNF Met mutation disrupts extinction and increases anxiety-like behaviors (Chen et al. 2006; Soliman et al. 2010). Interestingly, genetic manipulations that increase BDNF expression in mice similarly increased anxiety-like behaviors, but decreased immobility in the forced swim test (Govindarajan et al. 2006). Moreover, BDNF overexpression in mice resulted in memory impairments

\footnotetext{
${ }^{4}$ These authors contributed equally to this work.

5 Present address: Behavioral Pharmacology Laboratory, New York State Institute for Basic Research in Developmental Disabilities, Staten Island, New York 10314, USA

${ }^{6}$ Corresponding author.

E-mail francesco.papaleo@iit.it.

Article is online at http://www.learnmem.org/cgi/doi/10.1101/Im.2213711.
}

on passive avoidance, eight-arm radial maze, and Morris watermaze tests (Croll et al. 1999; Cunha et al. 2009). Thus, current evidence indicates that genetic mutations that both decrease and increase BDNF levels might have detrimental effects.

The present experiments were designed to extend the evaluation of behavioral phenotypes in BDNF overexpressing transgenic mice (BDNF-tg) on additional cognitive tasks and several other behavioral domains in which BDNF has been implicated. Our experiments tested only female BDNF-tg and WT littermates, since females have not been tested previously and we wanted to discover whether females showed phenotypes similar to those reported for males. This approach enables the investigation of the life-long effects of genetic variation as a result of a relative increase of BDNF expression as found in humans with functional genetic modifications in the BDNF gene. We compared BDNF-tg and WT littermates on a T-maze working memory task that is dependent on the prefrontal cortex (PFC) (Kellendonk et al. 2006) and on contextual and cued fear conditioning that is dependent on the hippocampus and amygdala (LeDoux 1996; Fanselow and Poulos 2005). In addition, we comprehensively evaluated measures of general health that could introduce artifacts in interpreting cognitive phenotypes. Lastly, we characterized BDNF-tg mice on a series of additional behaviors relevant to different psychiatric disorders including anxiety, depression, schizophrenia, epilepsy, and autism.

\section{Results}

\section{Overexpression of mature BDNF in BDNF-tg}

The amount of BDNF overexpression in male mice of this line was previously reported as approximately fivefold higher for mRNA and 1.8- to 12-fold higher for protein levels in neocortex, hippocampus, amygdala, and striatum (Huang et al. 1999; Govindarajan et al. 2006; Cunha et al. 2009). To evaluate BDNF protein overexpression in behaviorally tested female BDNF-tg mice in the present colony, we performed a BDNF-specific quantitative ELISA. Quantitative assessment of total BDNF protein levels 
in the PFC showed $\sim 3.5$-fold higher BDNF levels in BDNF-tg as compared with WT littermate females $(t=-5.13 ; \mathrm{df}=21 ; P<$ 0.0001 ) (Fig. 1A). Similarly, $\sim 1.7$-fold higher BDNF levels in the hippocampus were present in BDNF-tg compared with WT littermates $(t=-3.32$; df $=16 ; P<0.005)$ (Fig. 1B). Activity-dependent BDNF neural secretion in BDNF-tg mice was not assayed in the present experiments, but will be important for future studies.

BDNF is initially synthesized as a precursor protein (pro$\mathrm{BDNF}$ ) that, following different cleavage processes, produces two isoforms of $\sim 28 \mathrm{kDa}$ (truncated BDNF) and $14 \mathrm{kDa}$ mature BDNF (mat-BDNF) (Seidah et al. 1999; Greenberg et al. 2009; Carlino et al. 2010). Both pro-BDNF and mat-BDNF are biologically active with suggestions that pro-BDNF and mat-BDNF elicit
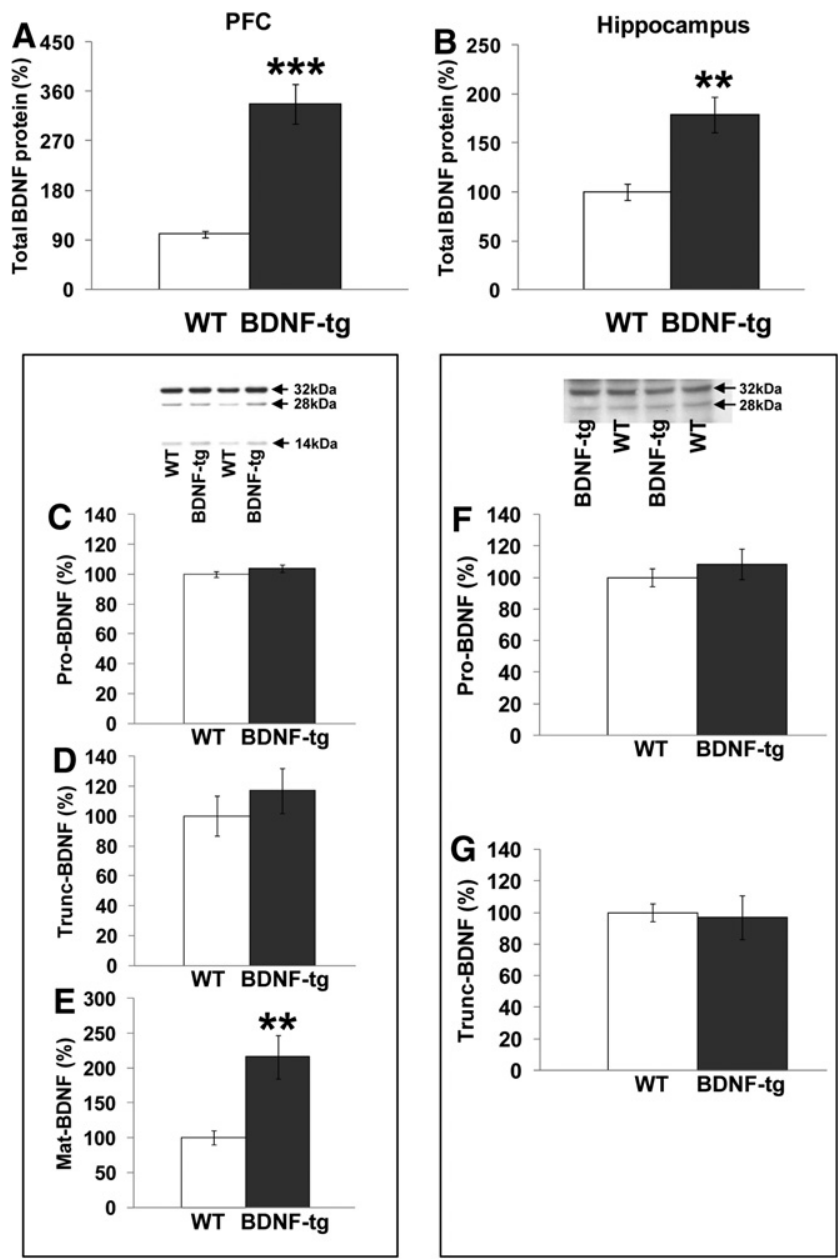

Figure 1. Elevated mature BDNF isoform in BDNF-tg mice. Tissue levels of total BDNF protein in $(A)$ the prefrontal cortex and $(B)$ the hippocampus of BDNF-tg and WT female littermates determined by ELISA. $\left(^{* *}\right) P<0.005$ and $\left(^{* *}\right) P<0.0001$ vs. WT littermates. For PFC: $n=9$ WT, $n=14$ BDNF-tg. For hippocampus: $n=7 \mathrm{WT}, n=11$ BDNF-tg. (C-E) Western blot with sc-546 (N-20) anti-BDNF antibody to determine $(C)$ precursor, $(D)$ truncated, and $(E)$ mature BDNF protein levels in the PFC of BDNF-tg and WT female littermates. BDNF increase in these BDNF-tg mice was primarily due to the mature form. (**) $P<0.005$ vs. WT littermates. $N=9$ WT, $n=9$ BDNF-tg. Western blot with AB9042 anti-proBDNF antibody, to determine $(F)$ precursor and $(G)$ truncated BDNF protein levels in the PFC of BDNF-tg and WT female littermates. $N=6 \mathrm{WT}, n=6$ BDNF-tg. Results are expressed as percentage of the WT group for each experiment. Values represent mean \pm SEM throughout Figures $1-8$. opposing synaptic effects through activation of distinct receptors: p75 ${ }^{\text {NTR }}$ and Trk receptor tyrosine kinases (Greenberg et al. 2009). Moreover, different levels of specific BDNF isoforms have been correlated with schizophrenia and its cognitive impairments (Carlino et al. 2010). BDNF-tg male mice show a significant increase in total BDNF levels without apparent changes in the pro-BDNF protein (Cunha et al. 2009). To investigate which specific BDNF isoforms are altered in the BDNF-tg mice, we assayed the different BDNF isoforms in the PFC of our mice. PFC matBDNF protein immunoreactivity was increased in female BDNFtg vs. WT littermates $(t=-3.56$; $\mathrm{df}=16 ; P<0.005)$ (Fig. $1 \mathrm{E})$. In contrast, no changes were present for truncated BDNF $(t=-0.84 ; \mathrm{df}=15 ; P=0.41)$ (Fig. 1D) and BDNF precursor isoforms $(t=-1.24 ; \mathrm{df}=16 ; P=0.23)$ (Fig. $1 \mathrm{C})$. The BDNF $(\mathrm{N}-20)$ : sc-546 antibody used might also cross react with other proteins around the same molecular weight as pro-BDNF (Matsumoto et al. 2008). Thus, we also used another antibody specific to pro-BDNF, confirming that our female BDNF-tg mice do not have increased levels of pro-BDNF $(t=-0.75 ; \mathrm{df}=10 ; P=0.47)$ (Fig. 1F) and trunc-BDNF $(t=0.20 ; \mathrm{df}=10 ; P=0.84$ ) (Fig. $1 \mathrm{G}$ ) in their PFC. These results demonstrate that the line of BDNF overexpressing mice used in the present behavioral experiments selectively overexpress the BDNF mature form.

\section{General health parameters in BDNF-tg}

Control measures of general health and motor functions were evaluated to detect any physical artifacts that could confound the interpretation of phenotypes on more complex behavioral tasks (Table 1). Grooming behavior in an empty cage was increased in BDNF-tg female mice as compared with WT littermates $(t=-3.68 ; \mathrm{df}=23 ; \quad P<0.005$ for grooming time; $t=-2.27 ; \mathrm{df}=23 ; P<0.05$ for number of grooming events). No BDNF genotype-dependent differences were present for body weight $(t=1.32 ; \mathrm{df}=23 ; P=0.20)$, and no BDNF-tg or WT littermates presented any abnormality in coat condition, whisker presence, piloerection, body and limb tone, and general physical aspect. No BDNF genotype-dependent differences were present for motor ability measures including wire hang $(t=-0.39$; $\mathrm{df}=$ 23; $P=0.70)$, rearing $(t=1.11 ; \mathrm{df}=23 ; P=0.28)$, and digging $(t=0.01 ; \mathrm{df}=23 ; P=0.99)$. Similarly, no BDNF-tg or WT littermates presented any abnormality in trunk curl, positional passivity, exploration, and reflexes including righting, eye blink, ear twitch, whisker twitch, forepaw reaching, and petting escape. No genotype differences were detected on pain responses measured in the hot plate $(t=0.87 ; \mathrm{df}=17 ; P=0.40)$ and tail-flick tests $(t=-0.18 ; \mathrm{df}=17 ; P=0.85)$. Thus, BDNF overexpression in female mice had no effect on most of the general health parameters measured, including physical characteristics and neurological reflexes, but did elevate self-grooming.

\section{Reduced breeding efficiency in BDNF-tg}

BDNF-tg females displayed poor breeding as compared with WT littermates. In particular, of the 19 pregnancies of BDNF-tg male $\times$ B6 female dams, 91 pups survived, with an average of about 4.5 pups per pregnancy. Of the 22 pregnancies of $\mathrm{B} 6$ male $\times$ BDNF-tg female dams, 53 pups survived, with an average of about 2.4 pups per pregnancy. Of the 17 pregnancies of BDNF-tg male $x$ BDNF-tg female dams, 0 pups survived. Female mice of both genotypes became pregnant and gave birth, but large numbers of pups from BDNF-tg dams died during the first $10 \mathrm{~d}$ of life. Causes for the miscarriages and pup mortalities are not known. Investigations of maternal behavior deficits or a variety of other factors represent an important subject for future investigation. Thus, for this line of genetically modified mice, a BDNF-tg male $x$ B6 female breeding scheme is suggested. It is useful to note that 
Table 1. Measures of general health and reflexes

\begin{tabular}{|c|c|c|}
\hline General health & WT (14) & BDNF-tg (11) \\
\hline Body weight (g) & $19.9 \pm 0.6$ & $18.9 \pm 0.5$ \\
\hline Poor coat condition (\%) & 0 & 0 \\
\hline Bald patches (\%) & 0 & 0 \\
\hline Missing whiskers (\%) & 0 & 0 \\
\hline Piloerection (\%) & 0 & 0 \\
\hline Body tone ( $\%$ of good) & 100 & 100 \\
\hline Limb tone (\% of good) & 100 & 100 \\
\hline Physical abnormalities (\%) & 0 & 0 \\
\hline \multicolumn{3}{|l|}{ Motoric abilities } \\
\hline Trunk curl (\%) & 100 & 100 \\
\hline Forepaw reaching (\%) & 100 & 100 \\
\hline Wire hang (sec) & $58.1 \pm 1.9$ & $59.0 \pm 1.0$ \\
\hline Positional passivity (\%) & 0 & 0 \\
\hline \multicolumn{3}{|l|}{ Reflexes (\% of mice normal) } \\
\hline Righting reflex (\%) & 100 & 100 \\
\hline Corneal (\%) & 100 & 100 \\
\hline Ear twitch (\%) & 100 & 100 \\
\hline Whisker twitch (\%) & 100 & 100 \\
\hline \multicolumn{3}{|l|}{ Reactivity } \\
\hline To handling (3-point scale) & $2.0 \pm 0.0$ & $2.0 \pm 0.0$ \\
\hline Petting escape (\%) & 100 & 100 \\
\hline \multicolumn{3}{|l|}{ Empty-cage behavior } \\
\hline Transfer freezing (\%) & 0 & 0 \\
\hline Wild running (\%) & 0 & 9 \\
\hline Exploration (3-point scale) & $2.0 \pm 0.0$ & $2.0 \pm 0.0$ \\
\hline Grooming (sec) & $8.0 \pm 1.8$ & $23.7 \pm 4.2^{* *}$ \\
\hline Grooming (events) & $2.7 \pm 0.5$ & $4.3 \pm 0.5^{*}$ \\
\hline Rearing (events) & $50.0 \pm 1.9$ & $47.3 \pm 1.4$ \\
\hline Digging (events) & $8.1 \pm 1.9$ & $8.1 \pm 3.5$ \\
\hline \multicolumn{3}{|l|}{ Pain sensitivity } \\
\hline Hot plate (latency in sec) & $10.5 \pm 0.8$ & $9.6 \pm 0.7$ \\
\hline Tail flick (latency in sec) & $3.2 \pm 0.8$ & $3.4 \pm 0.6$ \\
\hline
\end{tabular}

$\left(^{*}\right) P<0.05 ;\left(^{* *}\right) P<0.005$ vs. WT littermates.

the pups that did survive displayed normal scores on measures of general health as adults.

\section{Working memory impairments in BDNF-tg}

On a discrete paired-trial T-maze working memory task, which depends on intact medial PFC functions (Kellendonk et al. 2006), all seven WT mice reached criterion. Six out of seven BDNF-tg mice also reached criterion. Among the mice that were able to learn this task, a genotype difference was detected for the number of days needed to reach the criterion for acquisition. WT mice required an average of $6.5 \mathrm{~d}$, while BDNF-tg littermates required an average of $11 \mathrm{~d}(t=-2.94 ; \mathrm{df}=11 ; P<0.01)$ (Fig. 2A). During the habituation phase of the task, no genotype difference was detected on latency to eat $\left(F_{(1,11)}=0.11 ; P=\right.$ 0.75) (Fig. 2B), which has been used as an index of simple reference memory and motivation to run to receive the food pellet reinforcers (Olton et al. 1979; Wenk 2001; Papaleo et al. 2008). There was a significant repeated measures effect $\left(F_{(1,11)}=14.03\right.$; $P<0.005$ ) (Fig. 2B), with all mice running faster on the second day of habituation to retrieve the reward pellets, independent of genotype.

Mice were then tested in the discrete paired-trial T-maze paradigm under more demanding conditions, consisting of four different intratrial delays, and decreasing the intertrial delay to $20 \mathrm{sec}$, instead of $20 \mathrm{~min}$. Analysis of the percentage of correct choices at the different intratrial delays revealed both a genotype effect $\left(F_{(1,44)}=19.07, P<0.0001\right)$ and a delay effect $\left(F_{(3,44)}=\right.$ 4.34, $P<0.01)$. All groups displayed delay-dependent performance, but BDNF-tg showed consistently worse performance compared with WT littermates $(P<0.0005)$ (Fig. 2C).
In response to the stress of placement in a new cage containing clean litter, the percentage of correct choices at the different intratrial delays again showed a genotype difference $\left(F_{(1,44)}=\right.$ 9.61, $P<0.005)$. BDNF-tg displayed impaired performance compared with WT littermates $(P<0.005)$ (Fig. 2D). These results indicate that in female mice genetic modifications resulting in increased BDNF expression lead to significant deficits in working memory.

Normal contextual and cued fear conditioning in BDNF-tg On fear conditioning, both genotypes displayed high levels of freezing subsequent to the CS-US pairings on the training day $\left(F_{(1,18)}=88.35, P<0.0001\right)$ (Fig. 3A). While genotypes did not differ on amount of baseline freezing prior to the CS-UCS pairings $\left(t_{(1,18)}=-1.14, P=0.16\right)$ (Fig. 3A), genotype differences were detected subsequent to the CS-US pairings $\left(F_{(1,18)}=6.57\right.$, $P<0.05$ ), and a genotype by phase of training interaction was significant $\left(F_{(1,18)}=10.25, P<0.01\right)$. Newman-Keuls post-hoc analysis indicates that BDNF-tg female mice freeze less than their WT littermates during the post-CS-UCS pairing on the training day $(P<0.05)$ (Fig. 3A). During the test for freezing to the identical context $24 \mathrm{~h}$ later, genotypes did not differ $\left(t_{(1,18)}=-1.14\right.$, $P=0.27$ ) (Fig. 3A). During testing of freezing to the auditory cue $48 \mathrm{~h}$ after training, both genotypes showed increased freezing scores during the cue presentation $\left(F_{(1,18)}=49.45, P<0.0001\right)$ (Fig. 3B), indicating that both genotypes associated the auditory cue with footshock $2 \mathrm{~d}$ after training. There was no effect of genotype on freezing either during the cue off or cue on phase $\left(F_{(1,18)}=1.58, P=0.22\right)$, and no significant interaction between genotype and cue $\left(F_{(2,48)}=3.53, P=0.08\right)$. Thus, associative learning and memory processes dependent on amygdala and/or hippocampus appear to be unaffected by BDNF overexpression.
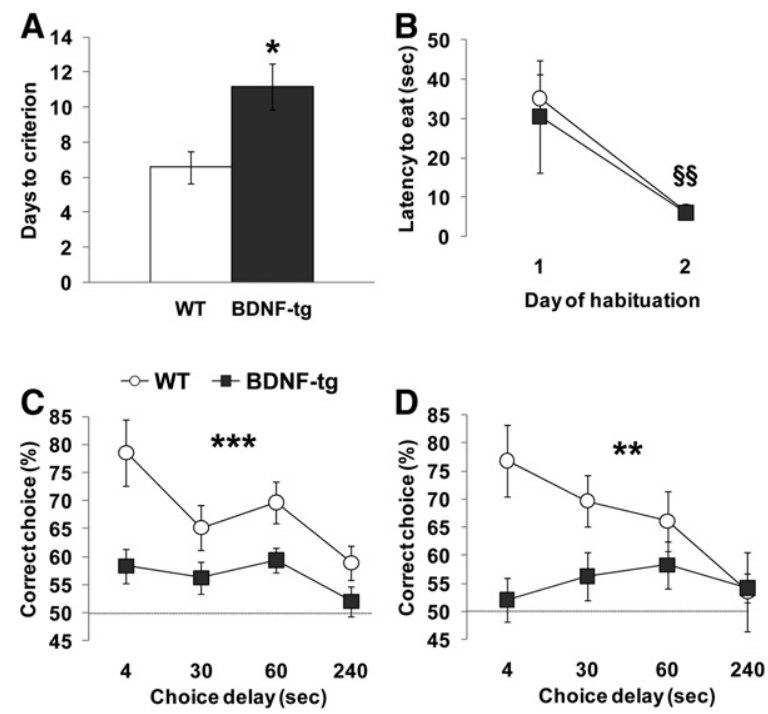

Figure 2. Working memory impairment in BDNF-tg. (A) Days to reach criteria and $(B)$ latency to retrieve the hidden food pellet displayed by WT and BDNF-tg littermates during training on the discrete paired-trial T-maze task. $(C, D)$ Percentage of correct choices displayed by the same WT and BDNF-tg littermates during the discrete paired-trial variable-delay T-maze test with different intratrial delays randomly presented (4, 30, 60, and $240 \mathrm{sec}$ ) and an intertrial delay of $20 \mathrm{sec}$ under normal conditions (C) and after the mild stress of placement in a new home cage 15 min before testing $(D)$. The dotted line corresponds to chance levels (50\%) of correct choices. (*) $P<0.05$, (**) $P<0.005$, and (***) $P<0.0005$ vs. WT littermates; $\left({ }^{\S \S}\right) P<0.0005$ vs. day 1 of the habituation. $N=7$ WT, $n=7$ BDNF-tg. 

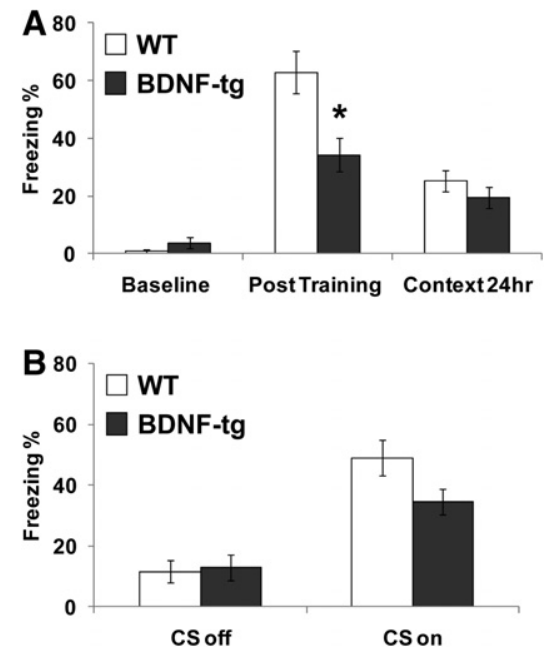

Figure 3. Normal cued and contextual fear conditioning in BDNF-tg. Mice were trained to learn an association of chamber context and a white noise cue to mild footshock during standard delay fear conditioning. Freezing behavior displayed by WT and BDNF-tg littermates $(A)$ at baseline, post-training, and $24 \mathrm{~h}$ after training in the identical context (context 24 h). (*) $P<0.05$ vs. WT littermates. (B) Freezing behavior during testing for cued conditioning in the altered context without (CS off) and with (CS on) the auditory cue, $48 \mathrm{~h}$ after training. $N=11 \mathrm{WT}$, $n=9$ BDNF-tg.

In contrast, the initial response to the footshock stress during the training session was lower in the female BDNF-tg.

\section{Acoustic startle and prepulse inhibition (PPI) impairments in BDNF-tg}

BDNF-tg showed lower acoustic startle reactivity to the 120-dB stimulus (genotype $\times$ acoustic sound interaction effect: $F_{(1,16)}=$ 4.61, $P<0.05$ ) (Fig. 4A), while levels of basal activity in the apparatus when no stimulus was presented did not differ $(P=0.90)$ (Fig. 4A). Analysis of PPI with a 120-dB acoustic startle stimulus showed a main genotype effect $\left(F_{(1,16)}=11.80, \quad P<0.005\right)$ (Fig. 4B), with BDNF-tg mice displaying less PPI than WT littermates $(P<0.005)$. Thus, these results suggest that genetic modifications resulting in increased BDNF protein expression decrease acoustic startle and PPI responses.

\section{Normal motor functions in BDNF-tg}

BDNF-tg and WT littermates showed no genotype differences in basal locomotor activity in the novel open field under dim lighting $\left(F_{(1,12)}=1.95, P=0.19\right)$ (Fig. 5A). Both genotypes decreased the distance traveled over time $\left(F_{(1,13)}=28.18, P<0.0001\right)$ (Fig. 5A), indicating normal habituation to the novelty of the open field arena.

BDNF-tg and WT littermates showed no genotype differences on the rotarod. Latency to fall over the eight trials increased, as expected, representing a significant effect of training $\left(F_{(1,16)}=\right.$ 12.15, $P<0.001$ ) (Fig. 5B). No genotype differences across trials $\left(F_{(1,16)}=0.33, P=0.57\right)$ and no genotype $\times$ training interaction effect was detected $\left(F_{(7,16)}=0.70, P=0.67\right)$. Thus, BDNF overexpression did not alter general locomotor activity or motor coordination in female mice.

\section{Increased seizure susceptibility in BDNF-tg}

At age 5-6 mo, four out of seven BDNF-tg females placed in a new cage with clean litter and bright room light $(\approx 820$ lux) displayed seizures, whereas none of the seven $\mathrm{WT}$ females displayed seizures when placed into a new cage with clean litter $(P<0.05)$ (Fig. 5C). Magnitudes of seizing were represented by stage 4 and/or 5 of the modified Racine's seizure scoring system (Croll et al. 1999). All seizures observed included bilateral forelimb clonus. Mice lost postural control and arched their backs, looking straight up. The observed seizures did not fit the definition of stage 6 , as the duration of individual seizures were too short (Fig. 5D). None of the seizure events resulted in death. Younger (2-mo-old) BDNF-tg female mice did not show any seizure events when exposed to a novel empty cage. Moreover, no mice showed a seizure event during any phase of the other behavioral tasks adopted. All of the other behavioral tests were conducted before age $5 \mathrm{mo}$ and under dim light conditions. Thus, the seizures induced by placing mice into a bright clean empty cage at ages 5-6 mo had no direct effect on any of the scores reported for other tests.

\section{Partial increase in anxiety-like traits in BDNF-tg}

In the light $\leftrightarrow$ dark test, BDNF-tg made fewer transitions between the light and the dark compartments $(t=2.72, \mathrm{df}=16, P<0.05)$ (Fig. 6A) and spent more time in the dark chamber $(t=-3.11$, $\mathrm{df}=16, P<0.01$ ) (Fig. 6B) as compared with WT littermates, representing an anxiety-like phenotype in the two major parameters of this approach-avoidance conflict task. No differences between genotypes were observed on the latency to first entry into the dark chamber $(t=-1.02, \mathrm{df}=16, P=0.32)$ (Fig. 6C).

In the elevated plus-maze, BDNF-tg and WT littermates did not differ on time spent in the open arms $(t=0.95, \mathrm{df}=17, P=$ $0.35)$ or number of entries into the open arms $(t=-0.92, \mathrm{df}=$ $17, P=0.37$ ) (Fig. 6D). Overall activity in the closed arms did not differ between genotypes ( $t=0.78, \mathrm{df}=17, P=0.45)$. Total number of arm entries did not differ between genotypes $(t=$ $0.68, \mathrm{df}=17, P=0.50$ ) (Fig. $6 \mathrm{E}$ ).

These results suggest that genetic overexpression of BDNF results in an increase in anxiety-like traits in female mice on one standard anxiety-related test for mice, but not on the other.

\section{Depression-related phenotypes are not altered in BDNF-tg}

To explore whether increased BDNF impacted depression-related phenotypes in female mice, BDNF-tg, and WT littermates were tested in two of the most widely used tests of mouse behaviors sensitive to antidepressant treatments, Porsolt forced swim and tail suspension. Similar immobility times were seen in BDNF-tg and WT littermates over the 4-min scoring portion of the 6-min forced swim task $(t=-1.19, \mathrm{df}=19, \quad P=0.25) \quad$ (Fig. 7A). Similar
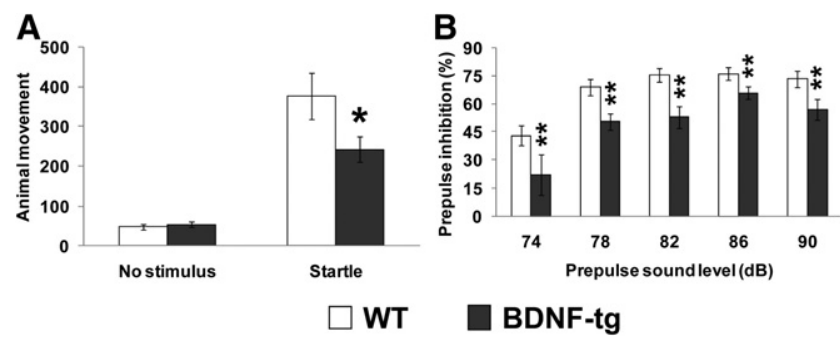

Figure 4. Acoustic startle and PPI are decreased in BDNF-tg. (A) Startle amplitude in WT and BDNF-tg female littermates during no stimulus trials and following the presentation of a 120-dB stimulus (startle). (B) Percent prepulse inhibition of the acoustic startle response displayed by the same mice after the presentation of $74,78,82,86$, and $90 \mathrm{~dB}$ prepulse sound stimuli. $N=9$ WT, $n=9$ BDNF-tg. (*) $P<0.05$ and (**) $P<0.005$ vs. WT littermates. 

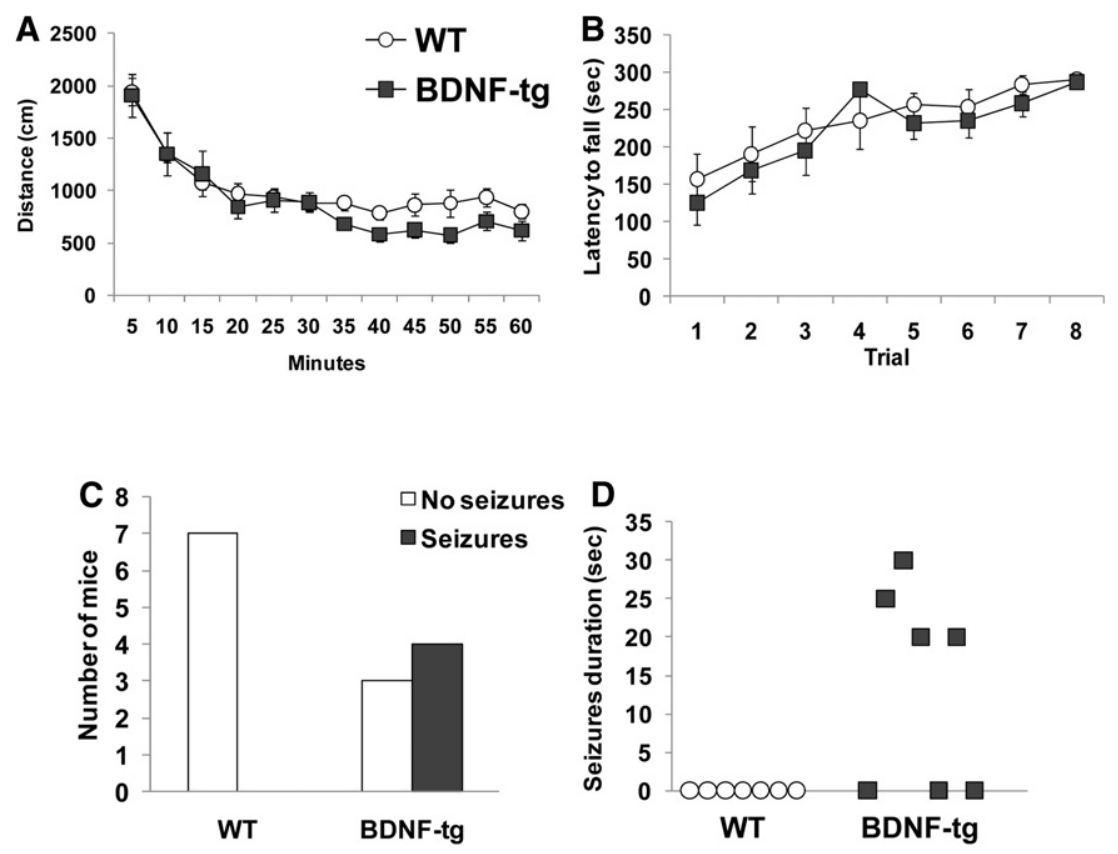

Figure 5. Normal locomotor abilities, but increased susceptibility to motor seizures in BDNF-tg. (A) Total distance traveled in 5-min intervals during the first 1 -h exposure to the open field arena. $N=7 \mathrm{WT}$, $n=7$ BDNF-tg. (B) Latency to fall from an accelerating rotarod, with a 300-sec maximum latency. Each subject was given eight total trials over $2 \mathrm{~d}$, four trials per day, with a 30-60-min intertrial interval. $N=$ $9 \mathrm{WT}, n=9$ BDNF-tg. (C) Number of BDNF-tg and WT littermates that seized or did not seize when placed in a bright, clean, empty cage for the 3-min general health evaluation. $(D)$ Duration of seizures (in seconds), during the 3-min physical health assessment in the clean empty cage. $N=7$ WT, $n=7$ BDNF-tg.

immobility times were seen in BDNF-tg and WT littermates in the tail suspension test $(t=-1.7, \mathrm{df}=19 ; P=0.10)$ (Fig. 7B). Thus, these results suggest that genetic overexpression of BDNF does not impact depression-like traits in female mice.

\section{Normal social abilities in BDNF-tg}

Sociability, defined as spending more time in the chamber with the novel mouse than in the chamber with the novel object, was significant in both WT $\left(F_{(1,9)}=268.8, P<0.0001\right)$ and BDNF-tg $\left(F_{(1,10)}=35.6, P<0.0001\right)$ (Fig. 8A) littermates. Similarly, the time spent sniffing the novel mouse was greater than the time spent sniffing the novel object for both WT $\left(F_{(1,9)}=59.8, \quad P<0.0001\right)$ and BDNF-tg $\left(F_{(1,10)}=59.3, \quad P<\right.$ 0.0001 ) (Fig. $8 \mathrm{~B}$ ) littermates. Entries into the left and right side chambers did not differ for WT $\left(F_{(1,10)}=1.14, P=0.31\right)$ or BDNF- $\operatorname{tg}\left(F_{(1,10)}=1.21, P=0.29\right)$ littermates, nor between genotypes $\left(F_{(1,19)}=1.82, P=0.19\right)($ Fig. $8 \mathrm{C})$. No innate side preference was observed across genotypes during the 10-min habituation session before the start of social testing (data not shown). Thus, these data indicate that general sociability was not impaired by excess BDNF expression.

\section{Discussion}

BDNF regulates synaptic plasticity in the brain and plays a critical role in maintaining normal PFC function (Savitz et al. 2006; Woo and $\mathrm{Lu} 2006$ ), leading to the hypothesis that BDNF may regulate working memory (Galloway et al. 2008). Previous reports from BDNF heterozygous knockouts and knockdowns revealed impairments in cognitive functions (Monteggia et al. 2004; Heldt et al. 2007). We predicted that BDNF overexpression could improve performance on cognitive tasks. Remarkably, our findings in female
BDNF-tg mice instead revealed that a genetically induced elevation in BDNF levels in the brain impaired working memory functions. BDNF-tg required more days to acquire a discrete pairedtrial alternation T-maze task than did their WT littermates. Moreover, during the discrete paired-trial variable-delay T-maze test, performance in the BDNFtg mice was significantly worse than WT littermate controls. These results clearly indicate that increased BDNF levels result in working memory deficits, at least in females. Consistent with our results, diminished working memory performance in aged female rats positively correlated with high BDNF levels in the PFC (Bimonte et al. 2003). Similarly, in male BDNF-tg mice, mild cognitive deficits were reported in an eight-arm radial maze protocol, in which each arm was baited and mice were allowed to move freely through them (Cunha et al. 2009). The paradigm adopted by Cunha and colleagues, however, might suffer from possible response patterns, because guillotine doors were not used and mice might choose the correct arms by response habits or memory for previous choices (Olton 1987). Thus, the paradigm used in males might not address working memory performance as specifically as an eight-arm radial maze delayed nonmatch to sample or win-shift protocol (Kesner and Holbrook 1987; Seamans et al. 1995; Papaleo et al. 2009). In contrast, the specific T-maze task used here better recapitulates elements of human working memory tasks and is dependent
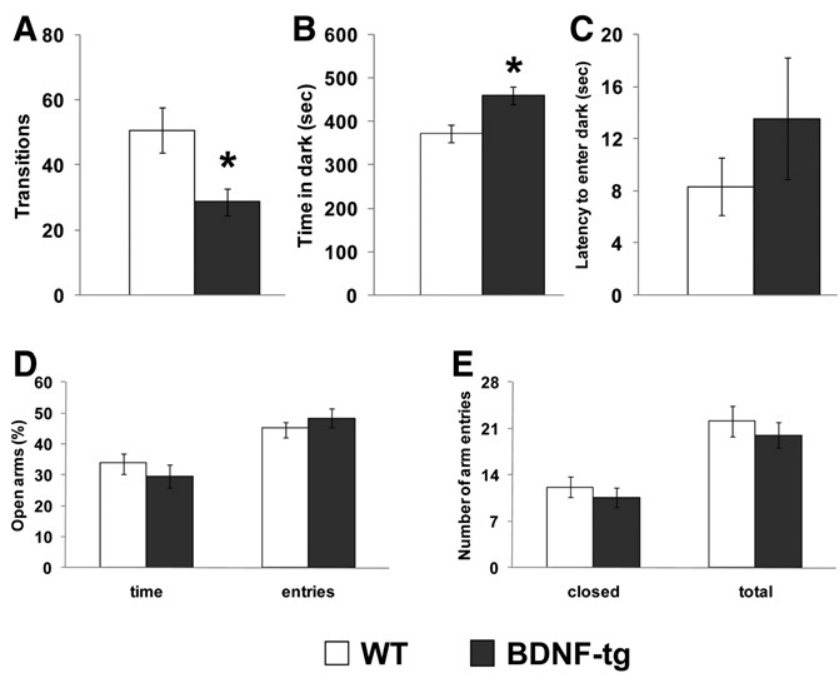

Figure 6. Anxiety-like phenotype in BDNF-tg on the light $\leftrightarrow$ dark test, but not on the elevated plus-maze. ( $A$ ) Transitions between the light and dark compartments in the light $\leftrightarrow$ dark exploration test; $\left(^{*}\right) P<0.05$ vs. WT littermates. $(B)$ Time spent in the dark chamber; $\left({ }^{*}\right) P<0.05$ vs. WT littermates. (C) Latency to enter the dark compartment. (D) Percentage of time spent in the open arms and number of visits to the open arms of an elevated plus-maze. (E) Total number of arm entries by WT and BDNF-tg littermates during the elevated plus-maze test. $N=9 \mathrm{WT}, n=$ 9 BDNF-tg. 

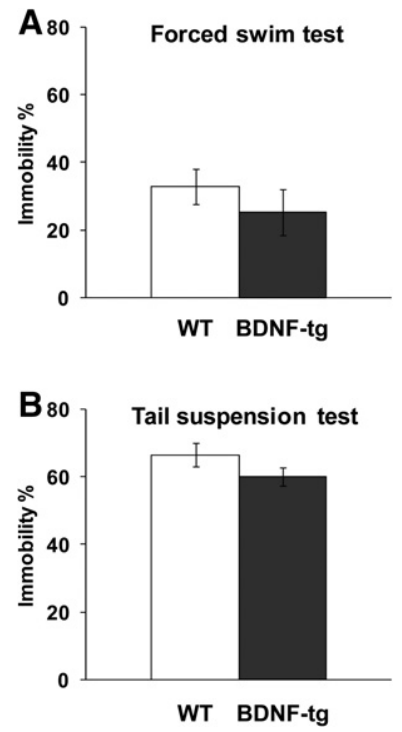

Figure 7. Normal depression-relevant immobility in female BDNF-tg mice. Percentage of time spent immobile during the last $4 \mathrm{~min}$ of the test session for the forced swim task $(A)$ and during the 6-min test session for the tail suspension task (B). $N=10 \mathrm{WT}, n=11 \mathrm{BDNF}$-tg for the forced swim task; $n=10 \mathrm{WT}, n=13 \mathrm{BDNF}$-tg for the tail suspension test.

on the medial PFC in mice (Aultman and Moghaddam 2001; Kellendonk et al. 2006; Papaleo et al. 2008). Considering these facts, it would be interesting in future studies to address the performance of BDNF-tg male mice in a discrete paired-trial variabledelay T-maze task.

Working memory deficits are core features of schizophrenia (Elvevag and Goldberg 2000). In the PFC of patients with schizophrenia, BDNF protein expression was reported to be reduced in cohorts that included a higher number of males (Wong et al. 2010), but PFC BDNF levels were higher in cohorts of schizophrenic patients when more females than males were included (Durany et al. 2001). Thus, these previous reports in humans and our present results in mice suggest that, especially in female subjects, functional genetic modifications that produce increased cortical BDNF levels might be detrimental to working memory.

Genetic reduction in BDNF impaired hippocampal-dependent cognition in mice (Gorski et al. 2003; Monteggia et al. 2004). Similarly, infusions of anti-BDNF antibodies or antisense BDNF oligonucleotides impaired spatial learning and memory in rats (Mu et al. 1999; Mizuno et al. 2000). Conversely, single intrahippocampal BDNF administration improved performance in the Morris water-maze test for spatial memory in adult rats (Cirulli et al. 2004). In agreement with these results, the BDNF Met variant, which reduces BDNF levels, is associated with poorer episodic memory and abnormal hippocampal activation in humans (Egan et al. 2003; Hariri et al. 2003). No genotype differences were detected between BDNF-tg and WT littermates on contextual or cued fear-conditioning components that are dependent on intact hippocampal and amygdala functions (LeDoux 1996; Fanselow and Poulos 2005). Less freezing after footshock was seen in BDNF-tg on the training day, although pain sensitivity did not differ between genotypes (Table 1), raising a point that will require future experiments to understand completely.

It is noteworthy that BDNF-tg female mice show features reminiscent of other schizophrenia models in animals, including working memory and PPI deficits. Acoustic startle and PPI are thought to be distinct behavioral responses with distinct mechanisms (Plappert et al. 2004). Phencyclidine treatments used as models of schizophrenia induce BDNF up-regulation in corticolimbic regions and disrupt PPI abilities (Jentsch and Roth 1999; Takahashi et al. 2006). Conversely, glutamate receptor $\varepsilon 2$ heterozygote mice that present reduced BDNF forebrain levels (Takahashi et al. 2006) show both increased acoustic startle and PPI responses (Takeuchi et al. 2001). Thus, the present findings extend earlier reports that support an interpretation that BDNF levels modulate sensorimotor gating.

BDNF-tg female mice were more prone to seizures when exposed to a new clean cage in a bright environment. Conventional transgenic mice that constitutively overexpress BDNF show increased seizure severity after kainic acid injection and increased hippocampal excitability (Croll et al. 1999). Conversely, BDNF heterozygote knockout mice have decreased seizures susceptibility (Kokaia et al. 1995). Limbic seizures increase BDNF expression in the brain and BDNF infusion induces seizures (Isackson et al. 1991; Duman and Vaidya 1998; Scharfman 2005). Moreover, there is evidence for an association between BDNF polymorphisms and partial epilepsy (Kanemoto et al. 2003) and between BDNF mRNA expression and epilepsy (Murray et al. 2000). Thus, these results strongly indicate a proconvulsant effect of increased BDNF levels in the brain, further highlighting BDNF as an interesting pharmacologic target for treating epilepsy.
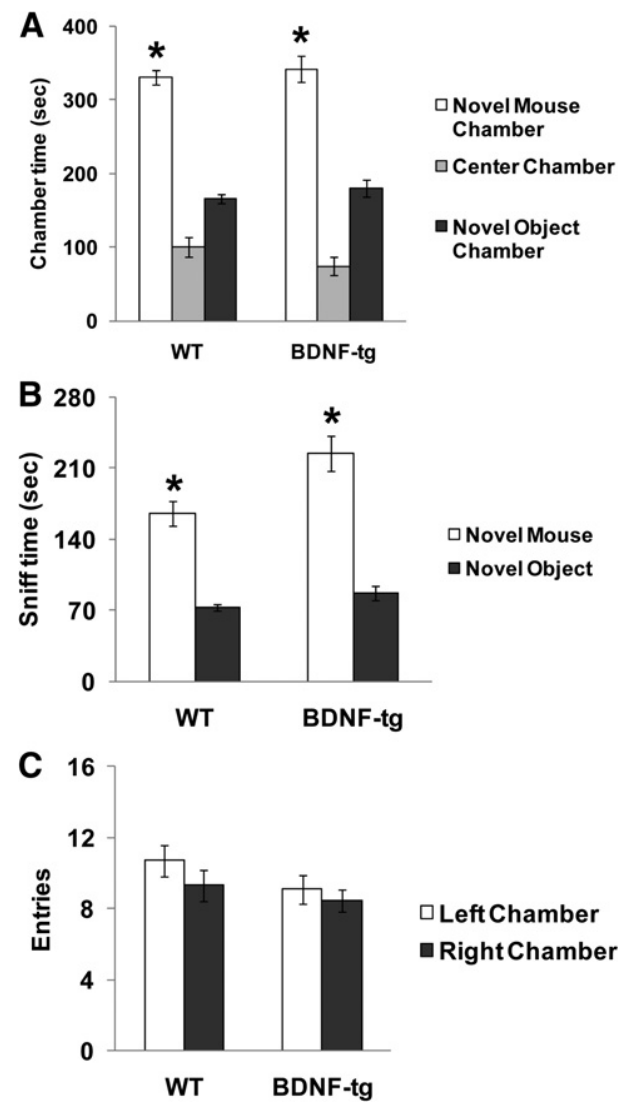

Figure 8. Normal sociability in female BDNF-tg mice. $(A)$ Time spent in the side chamber with the novel mouse, in the side chamber with the novel object and in the empty center chamber during the sociability test in an automated photocell-equipped three-chambered arena. Both genotypes spent more time in the side chamber with the novel mouse vs. time spent in the side chamber with the novel object; $\left(^{*}\right) P<0.05$. $(B)$ Both genotypes displayed significantly more time spent sniffing the novel mouse than time spent sniffing the novel object; $\left(^{*}\right) P<0.05$. (C) No genotype differences were seen in the number of entries into the side chambers. $N=9 \mathrm{WT}, n=11$ BDNF-tg. 
High self-grooming in rodents is often consistent with higher stress responses and anxiety-like phenotypes (Kalueff and Tuohimaa 2005; Shmelkov et al. 2010). BDNF-tg female mice showed a moderate anxiety-like phenotype as compared with WT littermates, consistent with a previous report in BDNF-tg male mice (Govindarajan et al. 2006). BDNF-tg displayed reduced transitions and increased time spent in the dark during the light $\leftrightarrow$ dark task. This was not an effect of altered exploratory locomotion, as no differences were present between BDNF-tg and WT littermates in the open field or on total arm entries in the elevated plus-maze. No genotype differences were detected in open arm entries in the elevated plus-maze. However, the elevated plusmaze test may be less sensitive to manipulations that change anxiety-like responses in female mice (File 2001). In previous reports, a cohort of male BDNF-tg mice displayed increased anxiety-like phenotypes (Govindarajan et al. 2006), whereas a study including both females and males of another line of BDNF overexpressing mice did not show altered anxiety-like behaviors using the elevated plus-maze task (Croll et al. 1999). Two independent lines of BDNF knockout female mice showed lower anxiety-like behaviors (Monteggia et al. 2007). Similarly, in humans, genetic variations that result in higher BDNF activitydependent release were associated with higher anxiety traits (Lang et al. 2005), while a genetic polymorphism reducing BDNF activity was protective against anxiety (Jiang et al. 2005). Taken together, these studies indicate that genetic variations that increased BDNF levels result in increased anxiety-related phenotypes, while those decreasing BDNF activity decreased anxiety-related phenotypes.

Female BDNF-tg did not differ from WT littermates on immobility times in either the Porsolt forced swim or tail suspension tests. In contrast, male BDNF-tg mice were reported to display lower depression-related immobility in the forced swim task (Govindarajan et al. 2006). This dichotomy is similar to findings in BDNF heterozygous mice, in which male heterozygous BDNF knockouts displayed higher immobility times on the forced swim test, while scores from females were comparable to their WT littermates (Advani et al. 2009). Similarly, male conditional BDNF knockout mice displayed normal depression-like behavior, while their female counterparts showed higher depression-like behavior (Monteggia et al. 2007; Autry et al. 2009). Finally, a recent meta-analysis revealed that a human functional BDNF genetic polymorphism is associated with a major depressive disorder, but with a sex-dependent effect (Verhagen et al. 2010). Thus, these findings suggest an interesting sexual dimorphism in the effects of BDNF genetic modifications on depression-related phenotypes.

BDNF genetic variations in humans might show sex differences on cognitive components, reactivity to stress, and predisposition to psychiatric illnesses (Raz et al. 2009; Shalev et al. 2009; Fukumoto et al. 2010; van Wingen et al. 2010; Verhagen et al. 2010; Pregelj et al. 2011). Similarly, genetic BDNF disruption in mice showed sex differences, at least for parameters such as locomotor activity, stress reactivity, and anxiety- and depression-like behaviors (Monteggia et al. 2007; Autry et al. 2009). To date, all previous studies investigating the effects of increased BDNF genetic modifications have used only males or have overlooked the distinct behavioral consequences in females (Chen et al. 2006; Govindarajan et al. 2006; Cunha et al. 2009; Yu et al. 2009; Soliman et al. 2010). It is important to consistently and separately study both sexes. In fact, females present specific behavioral characteristics in cognitive disorders and psychiatric abnormalities such as schizophrenia, anxiety, depression, drug addiction, epilepsy, and autism (Kessler et al. 1993; Aleman et al. 2003; Knickmeyer and Baron-Cohen 2006; Papaleo and Contarino 2006; McHugh and Delanty 2008; Andreano and
Cahill 2009; Grant et al. 2009). In this study we reported the behavioral consequences of a genetic modification that increased BDNF in females.

The present studies demonstrate that transgenic overexpression of BDNF impairs performance on a PFC-dependent working memory task, impairs sensorimotor gating abilities, confers susceptibility to seizures, increases some components of anxiety-related behaviors, increases self-grooming, and reduces reproductive success. Our comprehensive phenotyping results yield a profile of normal general health, neurological reflexes, motor functions, hippocampal-dependent learning and memory, depression-related behaviors, and social behavior in female mice overexpressing BDNF. Increased BDNF expression may play a larger role in PFC-dependent executive functions, demonstrating that both excess and insufficient BDNF can be detrimental to some cognitive abilities, but in different specific domains (Gorski et al. 2003; Monteggia et al. 2004; Chen et al. 2006; Govindarajan et al. 2006; Cunha et al. 2009). It is important to note that the present study demonstrates the behavioral effects in adulthood of increased BDNF expression throughout the lifespan, but does not address the behavioral effects of acute manipulations of BDNF. Our findings converge on human association studies evaluating the effects of BDNF functional genetic modifications in cognitive abilities and vulnerability to psychiatric disorders. It would be of interest for future studies to understand when the present behavioral abnormalities first appear during development and their correlated developmental dysfunctions. Understanding the molecular mechanism(s) underlying the BDNF genetic impact in mental illnesses may lead to the development of individualized therapeutic strategies that target the consequences of harboring unusual BDNF alleles.

\section{Materials and Methods}

\section{Subjects}

All procedures were approved by the NIMH Animal Care and Use Committee and followed the NIH Guidelines "Using Animals in Intramural Research." Breeding pairs of male and female hemizygous BDNF transgenic mice (BDNF-tg) were purchased from The Jackson Laboratory (Bar Harbor, ME) and housed in a conventional vivarium at the National Institute of Mental Health (Bethesda, MD). Breeding at NIMH was conducted with three approaches: BDNF-tg males bred with C57BL/6J (B6) females, B6 males bred with BDNF-tg females, and BDNF-tg males bred with BDNF-tg females. As described in the Results section, only the first two approaches produced viable litters, with the highest yield obtained from matings of BDNF-tg males and B6 females. Breeding efficiency issues described in the Results section limited the available numbers of mice for behavioral testing. Because practical issues limited the availability of male mice, the present experiments were conducted with females only. Littermates were used for all experiments. This line of BDNF-tg mice, which was originally generated on a CaMKII $\alpha$ promoter by Huang and coworkers at the Massachusetts Institute of Technology, overexpresses BDNF primarily in the brain (Huang et al. 1999). The genetic background for the original line was B6, permitting maintenance of the B6 background for the present experiments. Mice bred in Bethesda were genotyped by PCR analysis of tail DNA. Identification was either by ear cuts, paw tattoos with animal tattoo ink (Ketchum green paste, Ketchum Manufacturing Inc.), or subcutaneous barcode chip implants (BioMedic Data Systems Inc.). Littermates were group housed by sex after weaning, two to four per cage, in a climate-controlled animal facility $\left(22^{\circ} \mathrm{C} \pm\right.$ $2^{\circ} \mathrm{C}$ ) and maintained on a 12-hr light/dark cycle, with free access to food and water, except for the T-maze experiment. All behavioral testing was conducted during the light phase of their circadian cycle. The female subject mice were not tested for estrus cycle, since the training and testing phases of the T-maze task 
lasted $4 \mathrm{~d}$ or more, thus spanning the entire estrus cycle and minimizing its effects on behavior. Similarly, estrus cycle was not tested for the single-day behavioral tasks, which were conducted across consecutive days, because we have not detected higher variance (standard error bars) among females as compared with males for these tasks. If estrus cycle introduced a major effect on a parameter, then much higher variability would be expected in a group of females that included mixed stages of their estrus cycles, which was not seen in the present datasets. Experimenters were blind to the genotype of the subject mice during behavioral testing sessions. Mice were handled by the experimenter on alternate days during the week preceding the tests. Mice were acclimated in a room adjacent to the testing room at least $1 \mathrm{~h}$ prior to the start of a behavioral test.

\section{BDNF protein quantification by ELISA}

Mice were sacrificed by cervical dislocation and decapitated. Brains were rapidly extracted, tissue regions of interest freshly microdissected, weighed, flash-frozen using isopentane, temporarily stored on dry ice, and stored long-term at $-70^{\circ} \mathrm{C}$. Tissue samples were homogenized in $20 \mathrm{vol}$ of homogenization buffer. The homogenates were incubated at $4{ }^{\circ} \mathrm{C}$ for $30 \mathrm{~min}$ and centrifuged at $14,000 \mathrm{~g}$ for $30 \mathrm{~min}$. BDNF protein levels were measured by enzyme-linked immunosorbent assay (ELISA). Sandwich-style ELISAs were performed using the Chemikine BDNF ELISA kit (Chemicon International) according to the manufacturer's instructions. Briefly, 96-well plates, coated with rabbit polyclonal antibodies generated against human BDNF, were incubated overnight at $4^{\circ} \mathrm{C}$ with $400 \mu \mathrm{L}$ of tissue sample and $10 \%$ BSA. Plates were washed thoroughly and incubated for $2-3 \mathrm{~h}$ at room temperature with diluted biotinylated mouse anti-BDNF monoclonal antibody. Plates were thoroughly washed again and incubated with diluted streptavidin-HRP conjugate solution. Plates were developed with the addition of streptavidin-enzyme substrate and stop solution. BDNF content was interpolated from standard curve runs for each plate (linear range of $0-500 \mathrm{pg} / \mathrm{mL}$ ). BDNF protein content was divided by tissue weight in each sample to determine the amount of peptide per microgram starting tissue.

\section{Immunoblotting}

The PFC was dissected from BDNF-tg and WT littermates. The dissected cortical area refers to medial PFC, which comprise anterior cingulate, prelimbic, and infralimbic cortices (Holmes and Wellman 2009). The brain tissues were then homogenized and diluted to $2 \mu \mathrm{g} / \mu \mathrm{L}$ of total protein content in lysis buffer. After being denatured, the same amount of protein from each sample was loaded onto precast $4 \%-12 \%$ Bis-TRIS polyacrylamide gels (Invitrogen), and proteins were separated by electrophoresis. Each gel contained a molecular weight marker ladder (SeeBlue Plus 2; Invitrogen) and pooled sample used for interblot normalization. Gels were transferred onto nitrocellulose membranes with the iBlot gel transfer system (Invitrogen) for $11 \mathrm{~min}$. Membranes were blocked for $1 \mathrm{~h}$ in 5\% milk in Tris buffered saline (TBS) with $0.1 \%$ Tween-20 (TBS-T) and then incubated with anti rabbit BDNF (N-20):sc-546 (1:500 dilution; Santa Cruz Biotechnology) or with anti pro-BDNF AB9042 (1:1000 dilution; Chemicon International). Blots were rinsed in TBS-T, incubated in the peroxidase-conjugated goat anti-rabbit $(1: 1,000$ dilution, Santa Cruz Biotechnology) separately for $1 \mathrm{~h}$ in 5\% milk in TBS-T, and rinsed in TBS-T. Blots were developed in ECL-plus (GE Healthcare) and exposed to Kodak Bio-Max film. Films were digitized using a scanner, and the resulting images were analyzed using the NIH Scion Image. The values for all samples were expressed as a percentage of the mean of WT on the same gel.

\section{Discrete paired-trial variable-delay T-maze task}

A cohort of naive female BDNF-tg and WT littermates of 3-mo-old was tested in a paired-trial nonmatch to sample T-maze task as described previously (Papaleo et al. 2008, 2010). Subject mice were presented with a sequence of randomly chosen forced runs, each followed by a choice run, so that they were required to integrate information held online (the forced run) with the learned rule (nonmatch to sample).

\section{Open field}

At least $2 \mathrm{wk}$ after the end of the T-maze task, the same mice were tested in a Plexiglas Digiscan automated open field (Accuscan; $42 \times 42 \times 30 \mathrm{~cm}$ ), evenly illuminated by overhead red lighting (9 \pm 1 lux), as previously described (Papaleo et al. 2008, 2010).

\section{Physical health}

Measures of general health and neurological reflexes were assayed in the same mice at least $10 \mathrm{~d}$ after the open field test and in another separate cohort of mice between 9 and 11 wk of age in an empty cage $(15 \times 15 \times 10 \mathrm{~cm})$ with sawdust bedding (Harlan Teklad) as previously described (Crawley 2007; Chadman et al. 2008; Papaleo et al. 2008, 2010).

\section{Seizures}

During the 3-min empty-cage observation test for the physical health assessment, seizure behavior was scored in the same mice used for the T-maze task at ages 5-6 mo and a separate cohort at 2 mo of age following a modification of Racine's seizure scoring system (Croll et al. 1999). Length of seizure time (in seconds) was simultaneously quantified. Seizures were defined as beginning when the mouse clearly displayed a tonic-clonic seizure and as ending when the mouse regained motor control.

\section{Acoustic startle response and prepulse inhibition (PPI)}

Four-month-old female BDNF-tg and WT littermates were tested in San Diego Instruments startle chambers using standard methods as described previously (Papaleo et al. 2008, 2010). In brief, a sudden acoustic stimulus elicits the startle response, while an acoustic, nonstartling prepulse preceding the startle stimulus inhibits the startle response (PPI). The startle response elicited by sudden sensory stimuli and its PPI are between the most widely studied phenotypes that are highly conserved across mammalian species.

\section{Elevated plus-maze, light $\leftrightarrow$ dark exploration, accelerating rotarod, social approach, cued and contextual fear conditioning, forced swim, and tail suspension tasks}

Tasks were performed in a separate cohort of mice. The order of testing was as follows:

1. Five-minute elevated plus-maze test at age 5-6 wk.

2. Ten-minute light $\leftrightarrow$ dark exploration at age $6-7 \mathrm{wk}$.

3. Five-minute rotarod (Ugo Basile accelerating rotarod for mice) at age $7-9$ wk.

4. Ten-minute adult social approach in a three-chambered apparatus at $8-10 \mathrm{wk}$.

5. Pain sensitivity on hot plate and tail flick at age 9-11 wk.

6. Contextual and cued fear conditioning (Med Associates), 1 and $2 \mathrm{~d}$ after training, respectively, at age 11-12 wk.

7. Porsolt forced swim and tail suspension at age 20-22 wk.

Each task was conducted using standardized procedures as previously described (Holmes et al. 2002; Bailey et al. 2007; Crawley 2007; Chadman et al. 2008).

\section{Statistical analysis}

Results are expressed as mean \pm standard error of the mean (SEM) throughout. Latency to eat the food reinforcer in the T-maze task was analyzed with a Two-Way Analysis of Variance (ANOVA), using genotype (BDNF-tg and WT) as the between-subjects factor and day of habituation (first or second) as a repeated measures within-subjects factor. Student's $t$-test was used to compare 
BDNF-tg vs. WT on BDNF expression levels in PFC and hippocampus, some general health parameters, seizure duration, days needed to reach criterion in the T-maze task, elevated plus-maze, light $\rightarrow$ dark exploration, and contextual fear conditioning. Twotailed Fisher exact analyses were used to compare genotypes for the other general health parameters. The percentage of mice of each genotype that reached criterion on the T-maze task and showed or did not show seizure behavior during the general health testing were compared with $2 \times 2 \chi^{2}$ analyses. A TwoWay ANOVA with genotype (BDNF-tg vs. WT) as one variable and intratrial delays $(4,30,60$, or $240 \mathrm{sec})$ as the second independent variable was used to examine the percentage of correct choices made in the T-maze task. Two-Way ANOVA with genotype (BDNF-tg vs. WT) as a between-subjects factor and within-session 5-min intervals as the within-subject factor was used to analyze the total distance traveled in the open-field arena. Accelerating rotarod, open-field locomotion, fear conditioning pre- and posttraining responses, and pre- and post-cue responses were analyzed with Repeated Measures ANOVA. Social approach was analyzed using a within-groups Repeated Measures ANOVA to compare time spent in the two side chambers of the sociability test apparatus. Since the time spent in each of the three chambers added to $10 \mathrm{~min}$, and therefore were not independent, the test condition factor compared time spent only in the right vs. left chambers. Center chamber times are shown in the graphs for illustrative purposes. Time spent sniffing the novel object vs. the novel mouse, and entries into the side chambers, were similarly analyzed by within groups Repeated Measures ANOVA. The accepted value for significance was $P<0.05$.

\section{Acknowledgments}

We thank Dr. J. Chen, S. Garcia, S. Turner, A. Bebensee, and K. Jenkins for excellent technical assistance. We thank Drs. D.R. Weinberger and M. Canossa for critical reading of the manuscript. This research was supported by the Intramural Research Program of the National Institute of Mental Health. F.P. was also supported by The Italian Institute of Technology and by the Marie Curie FP7-Reintegration grant no. 268247.

\section{References}

Advani T, Koek W, Hensler JG. 2009. Gender differences in the enhanced vulnerability of BDNF+ $/-$ mice to mild stress. Int $J$ Neuropsychopharmacol 12: $583-588$.

Aleman A, Kahn RS, Selten JP. 2003. Sex differences in the risk of schizophrenia: Evidence from meta-analysis. Arch Gen Psychiatry 60: $565-571$.

Andreano JM, Cahill L. 2009. Sex influences on the neurobiology of learning and memory. Learn Mem 16: 248-266.

Aultman JM, Moghaddam B. 2001. Distinct contributions of glutamate and dopamine receptors to temporal aspects of rodent working memory using a clinically relevant task. Psychopharmacology 153: 353-364.

Autry AE, Adachi M, Cheng P, Monteggia LM. 2009. Gender-specific impact of brain-derived neurotrophic factor signaling on stress-induced depression-like behavior. Biol Psychiatry 66: 84-90.

Bailey KR, Pavlova MN, Rohde AD, Hohmann JG, Crawley JN. 2007 Galanin receptor subtype 2 (GalR2) null mutant mice display an anxiogenic-like phenotype specific to the elevated plus-maze. Pharmacol Biochem Behav 86: 8-20.

Baquet ZC, Gorski JA, Jones KR. 2004. Early striatal dendrite deficits followed by neuron loss with advanced age in the absence of anterograde cortical brain-derived neurotrophic factor. J Neurosci 24: 4250-4258.

Bekinschtein P, Cammarota M, Izquierdo I, Medina JH. 2008. BDNF and memory formation and storage. Neuroscientist 14: 147-156.

Bimonte HA, Nelson ME, Granholm AC. 2003. Age-related deficits as working memory load increases: Relationships with growth factors. Neurobiol Aging 24: 37-48.

Carlino D, Leone E, Di Cola F, Baj G, Marin R, Dinelli G, Tongiorgi E, De Vanna M. 2010. Low serum truncated-BDNF isoform correlates with higher cognitive impairment in schizophrenia. J Psychiatr Res 45: $273-279$.

Chadman KK, Gong S, Scattoni ML, Boltuck SE, Gandhy SU, Heintz N, Crawley JN. 2008. Minimal aberrant behavioral phenotypes of neuroligin-3 R451C knockin mice. Autism Res 1: 147-158.
Chaldakov GN, Tonchev AB, Aloe L. 2009. NGF and BDNF: From nerves to adipose tissue, from neurokines to metabokines. Riv Psichiatr 44: $79-87$.

Chen ZY, Jing D, Bath KG, Ieraci A, Khan T, Siao CJ, Herrera DG, Toth M, Yang C, McEwen BS, et al. 2006. Genetic variant BDNF (Val66Met) polymorphism alters anxiety-related behavior. Science $\mathbf{3 1 4}$ : $140-143$.

Chen LY, Rex CS, Sanaiha Y, Lynch G, Gall CM. 2010. Learning induces neurotrophin signaling at hippocampal synapses. Proc Natl Acad Sci 107: 7030-7035.

Cirulli F, Berry A, Chiarotti F, Alleva E. 2004. Intrahippocampal administration of BDNF in adult rats affects short-term behavioral plasticity in the Morris water maze and performance in the elevated plus-maze. Hippocampus 14: 802-807.

Crawley JN. 2007. What's wrong with my mouse? Behavioral phenotyping of transgenic and knockout mice. John Wiley \& Sons, Inc., Hoboken, NJ.

Croll SD, Suri C, Compton DL, Simmons MV, Yancopoulos GD, Lindsay RM, Wiegand SJ, Rudge JS, Scharfman HE. 1999. Brain-derived neurotrophic factor transgenic mice exhibit passive avoidance deficits, increased seizure severity and in vitro hyperexcitability in the hippocampus and entorhinal cortex. Neuroscience 93: 1491-1506.

Cunha C, Angelucci A, D'Antoni A, Dobrossy MD, Dunnett SB, Berardi N, Brambilla R. 2009. Brain-derived neurotrophic factor (BDNF) overexpression in the forebrain results in learning and memory impairments. Neurobiol Dis 33: 358-368.

Dempster E, Toulopoulou T, McDonald C, Bramon E, Walshe M, Filbey F, Wickham H, Sham PC, Murray RM, Collier DA. 2005. Association between BDNF val66 met genotype and episodic memory. Am J Med Genet B Neuropsychiatr Genet 134B: $73-75$.

Duman RS, Vaidya VA. 1998. Molecular and cellular actions of chronic electroconvulsive seizures. J ECT 14: 181-193.

Duman RS, Monteggia LM. 2006. A neurotrophic model for stress-related mood disorders. Biol Psychiatry 59: 1116-1127.

Durany N, Michel T, Zochling R, Boissl KW, Cruz-Sanchez FF, Riederer P, Thome J. 2001. Brain-derived neurotrophic factor and neurotrophin 3 in schizophrenic psychoses. Schizophr Res 52: 79-86.

Egan MF, Kojima M, Callicott JH, Goldberg TE, Kolachana BS, Bertolino A, Zaitsev E, Gold B, Goldman D, Dean M, et al. 2003. The BDNF val66met polymorphism affects activity-dependent secretion of BDNF and human memory and hippocampal function. Cell 112: 257-269.

Elvevag B, Goldberg TE. 2000. Cognitive impairment in schizophrenia is the core of the disorder. Crit Rev Neurobiol 14: 1-21.

Fanselow MS, Poulos AM. 2005. The neuroscience of mammalian associative learning. Annu Rev Psychol 56: 207-234.

File SE. 2001. Factors controlling measures of anxiety and responses to novelty in the mouse. Behav Brain Res 125: 151-157.

Fukumoto N, Fujii T, Combarros O, Kamboh MI, Tsai SJ, Matsushita S, Nacmias B, Comings DE, Arboleda H, Ingelsson M, et al. 2010. Sexually dimorphic effect of the Val66Met polymorphism of BDNF on susceptibility to Alzheimer's disease: New data and meta-analysis. Am J Med Genet B Neuropsychiatr Genet 153B: 235-242.

Galloway EM, Woo NH, Lu B. 2008. Persistent neural activity in the prefrontal cortex: A mechanism by which BDNF regulates working memory? Prog Brain Res 169: 251-266.

Genoud C, Knott GW, Sakata K, Lu B, Welker E. 2004. Altered synapse formation in the adult somatosensory cortex of brain-derived neurotrophic factor heterozygote mice. I Neurosci 24: 2394-2400.

Goldberg TE, Weinberger DR. 2004. Genes and the parsing of cognitive processes. Trends Cogn Sci 8: 325-335.

Gorski JA, Balogh SA, Wehner JM, Jones KR. 2003. Learning deficits in forebrain-restricted brain-derived neurotrophic factor mutant mice. Neuroscience 121: 341-354.

Govindarajan A, Rao BS, Nair D, Trinh M, Mawjee N, Tonegawa S, Chattarji S. 2006. Transgenic brain-derived neurotrophic factor expression causes both anxiogenic and antidepressant effects. Proc Natl Acad Sci 103: 13208-13213.

Grant BF, Goldstein RB, Chou SP, Huang B, Stinson FS, Dawson DA, Saha TD, Smith SM, Pulay AJ, Pickering RP, et al. 2009. Sociodemographic and psychopathologic predictors of first incidence of DSM-IV substance use, mood and anxiety disorders: Results from the Wave 2 National Epidemiologic Survey on Alcohol and Related Conditions. Mol Psychiatry 14: 1051-1066.

Gratacos M, Gonzalez JR, Mercader JM, de Cid R, Urretavizcaya M, Estivill X. 2007. Brain-derived neurotrophic factor Val66Met and psychiatric disorders: Meta-analysis of case-control studies confirm association to substance-related disorders, eating disorders, and schizophrenia. Biol Psychiatry 61: 911-922.

Greenberg ME, Xu B, Lu B, Hempstead BL. 2009. New insights in the biology of BDNF synthesis and release: Implications in CNS function. $J$ Neurosci 29: 12764-12767.

Hariri AR, Goldberg TE, Mattay VS, Kolachana BS, Callicott JH, Egan MF, Weinberger DR. 2003. Brain-derived neurotrophic factor val66met 
polymorphism affects human memory-related hippocampal activity and predicts memory performance. J Neurosci 23: 6690-6694.

Heldt SA, Stanek L, Chhatwal JP, Ressler KJ. 2007. Hippocampus-specific deletion of BDNF in adult mice impairs spatial memory and extinction of aversive memories. Mol Psychiatry 12: 656-670.

Holmes A, Wellman CL. 2009. Stress-induced prefrontal reorganization and executive dysfunction in rodents. Neurosci Biobehav Rev 33: $773-783$.

Holmes A, Yang RJ, Murphy DL, Crawley JN. 2002. Evaluation of antidepressant-related behavioral responses in mice lacking the serotonin transporter. Neuropsychopharmacology 27: 914-923.

Huang ZJ, Kirkwood A, Pizzorusso T, Porciatti V, Morales B, Bear MF, Maffei L, Tonegawa S. 1999. BDNF regulates the maturation of inhibition and the critical period of plasticity in mouse visual cortex. Cell 98: $739-755$

Isackson PJ, Huntsman MM, Murray KD, Gall CM. 1991. BDNF mRNA expression is increased in adult rat forebrain after limbic seizures: Temporal patterns of induction distinct from NGF. Neuron 6: 937-948.

Jentsch JD, Roth RH. 1999. The neuropsychopharmacology of phencyclidine: From NMDA receptor hypofunction to the dopamine hypothesis of schizophrenia. Neuropsychopharmacology 20: 201-225.

Jiang X, Xu K, Hoberman J, Tian F, Marko AJ, Waheed JF, Harris CR, Marini AM, Enoch MA, Lipsky RH. 2005. BDNF variation and mood disorders: A novel functional promoter polymorphism and Val66Met are associated with anxiety but have opposing effects. Neuropsychopharmacology 30: 1353-1361.

Kalueff AV, Tuohimaa P. 2005. Contrasting grooming phenotypes in three mouse strains markedly different in anxiety and activity (129S1, BALB/ c and NMRI). Behav Brain Res 160: 1-10.

Kanemoto K, Kawasaki J, Tarao Y, Kumaki T, Oshima T, Kaji R, Nishimura M. 2003. Association of partial epilepsy with brain-derived neurotrophic factor (BDNF) gene polymorphisms. Epilepsy Res 53: $255-258$.

Kellendonk C, Simpson EH, Polan HJ, Malleret G, Vronskaya S, Winiger V, Moore H, Kandel ER. 2006. Transient and selective overexpression of dopamine D2 receptors in the striatum causes persistent abnormalities in prefrontal cortex functioning. Neuron 49: 603-615.

Kesner RP, Holbrook T. 1987. Dissociation of item and order spatial memory in rats following medial prefrontal cortex lesions. Neuropsychologia 25: 653-664.

Kessler RC, McGonagle KA, Swartz M, Blazer DG, Nelson CB. 1993. Sex and depression in the National Comorbidity Survey. I: Lifetime prevalence, chronicity and recurrence. J Affect Disord 29: 85-96.

Knickmeyer RC, Baron-Cohen S. 2006. Fetal testosterone and sex differences in typical social development and in autism. J Child Neurol 21: $825-845$.

Kokaia M, Ernfors P, Kokaia Z, Elmer E, Jaenisch R, Lindvall O. 1995. Suppressed epileptogenesis in BDNF mutant mice. Exp Neurol 133: 215-224.

Lang UE, Hellweg R, Kalus P, Bajbouj M, Lenzen KP, Sander T, Kunz D, Gallinat J. 2005. Association of a functional BDNF polymorphism and anxiety-related personality traits. Psychopharmacology 180: 95-99.

LeDoux J. 1996. Emotional networks and motor control: A fearful view. Prog Brain Res 107: 437-446.

Lynch G, Rex CS, Chen LY, Gall CM. 2008. The substrates of memory: Defects, treatments, and enhancement. Eur J Pharmacol 585: 2-13.

Martinowich K, Manji H, Lu B. 2007. New insights into BDNF function in depression and anxiety. Nat Neurosci 10: 1089-1093.

Matsumoto T, Rauskolb S, Polack M, Klose J, Kolbeck R, Korte M, Barde YA. 2008. Biosynthesis and processing of endogenous BDNF: CNS neurons store and secrete BDNF, not pro-BDNF. Nat Neurosci 11: 131-133.

McHugh JC, Delanty N. 2008. Epidemiology and classification of epilepsy: Gender comparisons. Int Rev Neurobiol 83: 11-26.

Mizuno M, Yamada K, Olariu A, Nawa H, Nabeshima T. 2000. Involvement of brain-derived neurotrophic factor in spatial memory formation and maintenance in a radial arm maze test in rats. J Neurosci $\mathbf{2 0}$ $7116-7121$

Monteggia LM, Barrot M, Powell CM, Berton O, Galanis V, Gemelli T, Meuth S, Nagy A, Greene RW, Nestler EJ. 2004. Essential role of brain-derived neurotrophic factor in adult hippocampal function. Proc Natl Acad Sci 101: 10827-10832.

Monteggia LM, Luikart B, Barrot M, Theobold D, Malkovska I, Nef S, Parada LF, Nestler EJ. 2007. Brain-derived neurotrophic factor conditional knockouts show gender differences in depression-related behaviors. Biol Psychiatry 61: 187-197.

Mu JS, Li WP, Yao ZB, Zhou XF. 1999. Deprivation of endogenous brain-derived neurotrophic factor results in impairment of spatial learning and memory in adult rats. Brain Res 835: 259-265.

Murray KD, Isackson PJ, Eskin TA, King MA, Montesinos SP, Abraham LA, Roper SN. 2000. Altered mRNA expression for brain-derived neurotrophic factor and type II calcium/calmodulin-dependent protein kinase in the hippocampus of patients with intractable temporal lobe epilepsy. J Comp Neurol 418: 411-422.

Olton DS. 1987. The radial arm maze as a tool in behavioral pharmacology. Physiol Behav 40: 793-797.

Olton DS, Becker JT, Handelmann GE. 1979. Hippocampus, space, and memory. Behav Brain Sci 2: 313-365.

Papaleo F, Contarino A. 2006. Gender- and morphine dose-linked expression of spontaneous somatic opiate withdrawal in mice. Behav Brain Res 170: $110-118$.

Papaleo F, Crawley JN, Song J, Lipska BK, Pickel J, Weinberger DR, Chen J. 2008. Genetic dissection of the role of catechol-O-methyltransferase in cognition and stress reactivity in mice. J Neurosci $\mathbf{2 8 :}$ $8709-8723$.

Papaleo F, Weinberger DR, Chen J. 2009. Animal models of genetic effects on cognition. In The genetics of cognitive neuroscience (ed. TE Goldberg, DR Weinberger), 51-94. The MIT Press, Cambridge, MA.

Papaleo F, Yang F, Garcia S, Chen J, Lu B, Crawley JN, Weinberger DR. 2010. Dysbindin-1 modulates prefrontal cortical activity and schizophrenia-like behaviors via dopamine/D2 pathways. Mol Psychiatry 10.1038/mp.2010.106.

Peters J, Dieppa-Perea LM, Melendez LM, Quirk GJ. 2010. Induction of fear extinction with hippocampal-infralimbic BDNF. Science 328: $1288-1290$.

Plappert CF, Pilz PK, Schnitzler HU. 2004. Factors governing prepulse inhibition and prepulse facilitation of the acoustic startle response in mice. Behav Brain Res 152: 403-412.

Pregelj P, Nedic G, Paska AV, Zupanc T, Nikolac M, Balazic J, Tomori M, Komel R, Seler DM, Pivac N. 2011. The association between brain-derived neurotrophic factor polymorphism (BDNF Val66Met) and suicide. J Affect Disord 128: 287-290.

Raz N, Rodrigue KM, Kennedy KM, Land S. 2009. Genetic and vascular modifiers of age-sensitive cognitive skills: Effects of COMT, BDNF, ApoE, and hypertension. Neuropsychology 23: 105-116.

Savitz J, Solms M, Ramesar R. 2006. The molecular genetics of cognition: Dopamine, COMT and BDNF. Genes Brain Behav 5: 311-328.

Scharfman HE. 2005. Brain-derived neurotrophic factor and epilepsy-A missing link? Epilepsy Curr 5: 83-88.

Schmidt HD, Duman RS. 2007. The role of neurotrophic factors in adult hippocampal neurogenesis, antidepressant treatments and animal models of depressive-like behavior. Behav Pharmacol 18: 391-418.

Seamans JK, Floresco SB, Phillips AG. 1995. Functional differences between the prelimbic and anterior cingulate regions of the rat prefrontal cortex. Behav Neurosci 109: 1063-1073.

Seidah NG, Mowla SJ, Hamelin J, Mamarbachi AM, Benjannet S, Toure BB, Basak A, Munzer JS, Marcinkiewicz J, Zhong M, et al. 1999. Mammalian subtilisin/kexin isozyme SKI-1: A widely expressed proprotein convertase with a unique cleavage specificity and cellular localization. Proc Natl Acad Sci 96: 1321-1326.

Shalev I, Lerer E, Israel S, Uzefovsky F, Gritsenko I, Mankuta D, Ebstein RP, Kaitz M. 2009. BDNF Val66Met polymorphism is associated with HPA axis reactivity to psychological stress characterized by genotype and gender interactions. Psychoneuroendocrinology 34: 382-388

Shmelkov SV, Hormigo A, Jing D, Proenca CC, Bath KG, Milde T, Shmelkov E, Kushner JS, Baljevic M, Dincheva I, et al. 2010. Slitrk5 deficiency impairs corticostriatal circuitry and leads to obsessivecompulsive-like behaviors in mice. Nat Med 16: 598-602.

Soliman F, Glatt CE, Bath KG, Levita L, Jones RM, Pattwell SS, Jing D, Tottenham N, Amso D, Somerville LH, et al. 2010. A genetic variant BDNF polymorphism alters extinction learning in both mouse and human. Science 327: 863-866.

Takahashi M, Kakita A, Futamura T, Watanabe Y, Mizuno M, Sakimura K, Castren E, Nabeshima T, Someya T, Nawa H. 2006. Sustained brain-derived neurotrophic factor up-regulation and sensorimotor gating abnormality induced by postnatal exposure to phencyclidine: Comparison with adult treatment. J Neurochem 99: 770-780.

Takeuchi T, Kiyama Y, Nakamura K, Tsujita M, Matsuda I, Mori H, Munemoto Y, Kuriyama H, Natsume R, Sakimura K, et al. 2001. Roles of the glutamate receptor $\varepsilon 2$ and $\delta 2$ subunits in the potentiation and prepulse inhibition of the acoustic startle reflex. Eur I Neurosci 14: $153-160$.

van Wingen G, Rijpkema M, Franke B, van Eijndhoven P, Tendolkar I, Verkes RJ, Buitelaar J, Fernandez G. 2010. The brain-derived neurotrophic factor Val66Met polymorphism affects memory formation and retrieval of biologically salient stimuli. Neuroimage 50: $1212-1218$.

Verhagen M, van der Meij A, van Deurzen PA, Janzing JG, Arias-Vasquez A, Buitelaar JK, Franke B. 2010. Meta-analysis of the BDNF Val66Met polymorphism in major depressive disorder: Effects of gender and ethnicity. Mol Psychiatry 15: 260-271. 
Wenk GL. 2001. Assessment of spatial memory using the T maze. Curr Protoc Neurosci 10.1002/0471142301.na0805bs04.

Wong J, Hyde TM, Cassano HL, Deep-Soboslay A, Kleinman JE, Weickert CS. 2010. Promoter specific alterations of brain-derived neurotrophic factor mRNA in schizophrenia. Neuroscience 169: 1071-1084.

Woo NH, Lu B. 2006. Regulation of cortical interneurons by neurotrophins: From development to cognitive disorders. Neuroscientist 12: 43-56.
Yu H, Wang Y, Pattwell S, Jing D, Liu T, Zhang Y, Bath KG, Lee FS, Chen ZY. 2009. Variant BDNF Val66Met polymorphism affects extinction of conditioned aversive memory. J Neurosci 29: 4056-4064.

Zuccato C, Cattaneo E. 2009. Brain-derived neurotrophic factor in neurodegenerative diseases. Nat Rev Neurol 5: 311-322.

Received March 15, 2011; accepted in revised form June 10, 2011. 


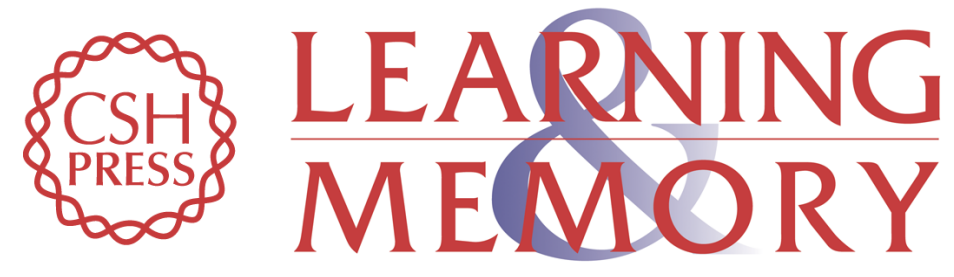

\section{Working memory deficits, increased anxiety-like traits, and seizure susceptibility in BDNF overexpressing mice}

Francesco Papaleo, Jill L. Silverman, Jordan Aney, et al.

Learn. Mem. 2011, 18:

Access the most recent version at doi:10.1101/lm.2213711

References This article cites 86 articles, 15 of which can be accessed free at: http://learnmem.cshlp.org/content/18/8/534.full.html\#ref-list-1

License

Email Alerting

Receive free email alerts when new articles cite this article - sign up in the box at the Service top right corner of the article or click here. 